\section{Idiopathic pulmonary haemosiderosis: a form of microscopic polyarteritis?}

B Leaker, G Cambridge, $R$ M du Bois, G H Neild

\begin{abstract}
Idiopathic pulmonary haemosiderosis remains a diagnosis of exclusion in patients who present with pulmonary alveolar haemorrhage. Systemic vasculitis developed in a patient with an eight year history of idiopathic pulmonary haemosiderosis. The diagnosis was confirmed by a rising titre of antineutrophil cytoplasmic antibodies directed against myeloperoxidase. Treatment with immunosuppressive agents resulted in complete resolution of symptoms and suppression of the antibodies. Measurement of antineutrophil cytoplasmic antibodies is recommended for all patients with pulmonar alveolar haemorrhage syndromes.
\end{abstract}

(Thorax 1992;47:988-990)

Alveolar haemorrhage is a recognised mode of presentation of several diseases, including microscopic polyarteritis. ${ }^{12}$ In many cases no underlying cause is found despite investigation. These cases are labelled as idiopathic pulmonary haemosiderosis, ${ }^{2}$ which remains a diagnosis of exclusion. We report a case of idiopathic pulmonary haemosiderosis in which systemic vasculitis developed eight years after the original presentation with haemoptysis, anaemia, and shadowing on the chest radiograph. This case emphasises the value of the measurement of antineutrophil cytoplasmic antibodies in patients with pulmonary haemorrhage, particularly during an acute episode. ${ }^{2}$

Department of Nephrology, Institute of Urology and Nephrology,

University College and Middlesex School of

Medicine, Middlesex

Hospital, London

W1N 8AA

B Leaker

G Cambridge

G H Neild

Interstitial Lung

Disease Unit, Royal

Brompton National

Heart and Lung

Hospital, London

SW3 6LR

$\mathrm{R} M$ du Bois

Reprint requests to:

Professor G H Neild

Accepted 15 February 1992

A 22 year old man had presented eight years previously with recurrent haemoptysis. Inves-

Results of serial pulmonary function tests monoxide transfer factor; $\mathrm{KCO}$-transfer coefficient. tigations revealed iron deficiency anaemia and his chest radiograph showed diffuse alveolar shadowing. The bronchoscopic appearances were normal but bronchial washings showed hemosiderin laden macrophages. An associated but asymptomatic feature was jejunal villous atrophy consistent with adult coeliac disease. No underlying cause for the haemoptysis could be found (an autoantibody screen and test for antiglomerular basement antibodies gave negative results) and a diagnosis of idiopathic pulmonary haemosiderosis was made by exclusion. He was reviewed regularly and continued to have repeated episodes of minor, self limiting haemoptysis, usually after a chest infection. At no time were there any symptoms or signs of systemic disease. After eight years he developed increasing breathlessness on exertion and presented with severe haemoptysis precipitated by infection. Examination disclosed line crackles in the chest but no other abnormality. His blood pressure was 100/70 $\mathrm{mm} \mathrm{Hg}$. The chest radiograph showed diffuse alveolar shadowing. Other investigations showed: haemoglobin $10 \mathrm{~g} / \mathrm{dl}$ with an iron deficient picture; erythrocyte sedimentation rate $80 \mathrm{~mm}$ in one hour; raised $C$ reactive protein, $80 \mathrm{mg} / \mathrm{l}$; raised plasma creatinine, $130 \mu \mathrm{mol} / \mathrm{l}$; complement $\mathrm{C} 3$ and $\mathrm{C} 4$ levels and results of liver function tests normal; ${ }^{51} \mathrm{Cr}$ EDTA glomerular filtration rate $70 \mathrm{ml} / \mathrm{min} /$ $1.73 \mathrm{~m}^{2}$; proteinuria, $0.5 \mathrm{~g} /$ day; microscopic haematuria with red cell casts. Lung function tests performed five days after admission showed a restrictive ventilatory defect with reduced transfer factor for carbon monoxide corrected for alveolar volume (KCO); arterial blood gas analysis at presentation showed: oxygen tension $4.8 \mathrm{kPa}$, carbon dioxide, $\mathrm{pH}$ $7 \cdot 48$, bicarbonate tension $4.6 \mathrm{kPa}, 27\left(\mathrm{FiO}_{2}\right.$ $0 \cdot 21$ ) (table). The Kco remained low during the acute episode, possibly because the test was performed late as the Kco usually returns to normal within 48 hours. $^{2}$ In addition, the low Kco may reflect the underlying pulmonary fibrosis, which had developed as a result of repeated episodes of pulmonary haemorrhage. Anti-glomerular basement membrane antibodies were not found. Antineutrophil cytoplasmic antibody was present with cytoplasmic pattern (titre 1/80). Enzyme linked immunosorbent assay (ELISA) showed that these antibodies were directed against myeloperoxidase (titre $1 / 80$ ) and not against serine proteinase 3. Serial studies on stored and subsequent serum samples are summarised in the figure. Renal biopsy showed segmental necrotising glomerulonephritis with crescents,

\begin{tabular}{|c|c|c|c|c|c|c|}
\hline & Predicted $^{\star}$ & 1981 & $\begin{array}{l}1987 \\
\text { (2y before } \\
\text { treatment) }\end{array}$ & $\begin{array}{l}\text { Sept } 1989 \\
\text { ( } 3 \text { mo before } \\
\text { treatment) }\end{array}$ & $\begin{array}{l}\text { Dec } 1989 \\
\text { (acute } \\
\text { illness) }\end{array}$ & $\begin{array}{l}\text { June } 1990 \\
\text { (follow up) }\end{array}$ \\
\hline $\begin{array}{l}\text { FEV }(\mathrm{ml}) \\
\text { FVC }(\mathrm{ml}) \\
\text { TLC (ml) } \\
\text { TLCO }(\mathrm{mmol} / \mathrm{min} / \mathrm{kPa}) \\
\mathrm{Kco}(\mathrm{mmol} / \mathrm{min} / \mathrm{kPa} / \mathrm{l})\end{array}$ & $\begin{array}{l}3660-4960 \\
4290-5810 \\
5330-7750 \\
9 \cdot 98-13 \cdot 5 \\
1 \cdot 63-2 \cdot 20\end{array}$ & $\begin{array}{l}3630 \\
4440 \\
5350 \\
8 \cdot 92 \\
1 \cdot 81\end{array}$ & $\begin{array}{r}2950 \\
3760 \\
5010 \\
4 \cdot 71 \\
1 \cdot 14\end{array}$ & $\begin{array}{l}2570 \\
3570 \\
5060 \\
4 \cdot 11 \\
0.96\end{array}$ & $\begin{array}{l}2330 \\
3290 \\
4970 \\
3 \cdot 32 \\
0 \cdot 85\end{array}$ & $\begin{array}{r}2580 \\
3770 \\
5000 \\
4.37 \\
1.00\end{array}$ \\
\hline
\end{tabular}

FEV - forced expiratory volume in one second; FVC—forced vital capacity; TLC—total lung capacity; TLco-carbon 
Titres of antineutrophil cytoplasmic antibodies as measured by indirect immunofluorescence from the time of the first sample (time 0), showing rising IgG titres until the acute illness. Titres fell rapidly after the introduction of immunosuppressive treatment.

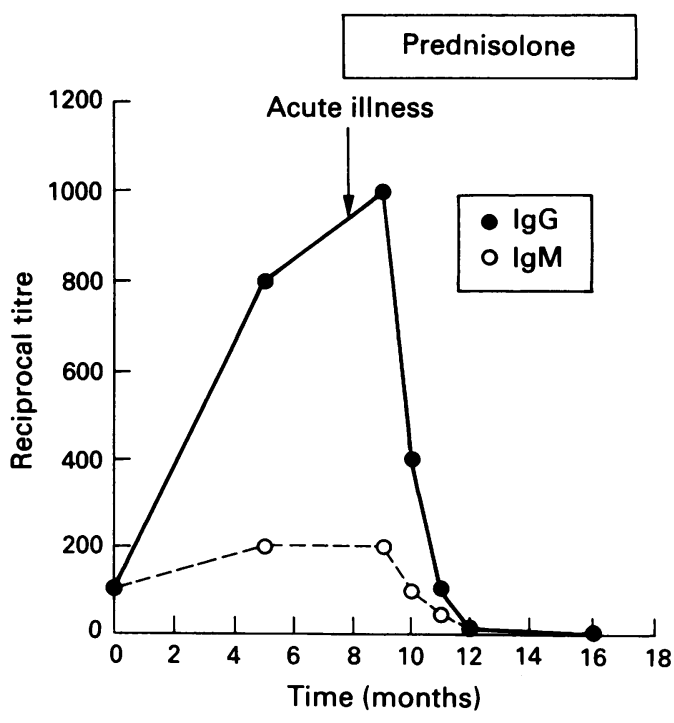

and the negative immunoperoxidase staining of biopsy material was consistent with a diagnosis of microscopic polyarteritis. Treatment was started with intravenous pulse methylprednisolone $0.5 \mathrm{~g}$ three times a day, followed by oral corticosteroids $20 \mathrm{mg}$ /day for four weeks tapering to a maintenance dose of $12.5 \mathrm{~g} /$ day over eight weeks, and cyclophosphamide $2 \cdot 0$ $\mathrm{mg} / \mathrm{kg} /$ day. Azathioprine $1.5 \mathrm{mg} / \mathrm{kg} /$ day was substituted for cyclophosphamide after one month. After one year's follow up there has been no recurrence of symptoms and the patient is symptom free with maintenance immunosuppression (prednisolone $12.5 \mathrm{mg}$ and azathioprine $125 \mathrm{mg} /$ day. The titre of antineutrophil cytoplasmic antibodies has fallen to zero according to both ELISA and indirect immunofluorescence. Results of lung function studies remain abnormal but have improved since the acute illness. His glomerular filtration rate is now normal at 120 $\mathrm{ml} / \mathrm{min} / 1 \cdot 73^{2}$.

\section{Discussion}

Alveolar haemorrhage may occur in association with several diseases; the term idiopathic pulmonary haemosiderosis is used when all known causes of pulmonary alveolar haemorrhage have been excluded. ${ }^{1}$ Our patient had longstanding pulmonary haemorrhage before the development of systemic symptoms. There was no evidence of systemic vasculitis during this period. His antineutrophil cytoplasmic antibodies titre became positive nine months before the start of his systemic illness and returned to normal with treatment, confirming his clinical and immunological remission. The coincidence of a rising antineutrophil cytoplasmic antibodies titre with acute alveolar haemorrhage supports the hypothesis that he had been suffering from a subclinical capillaritis which became overt both clinically and immunologically during his recent exacerbation.

Although the cause of idiopathic pulmonary haemosiderosis is unknown, an association with adult coeliac disease has been described, which suggests immune mechanisms. ${ }^{1}$ Immunofluorescence ${ }^{1}$ and electron microscopic ${ }^{3}$ studies, however, have not shown features suggesting immunoglobulin or immune complex deposition, although ultrastructurally endothelial cell and capillary basement membrane damage has been observed. ${ }^{3}$ Exacerbations of idiopathic pulmonary haemosiderosis may occur with symptoms of infection, as in this case, and we may speculate that, against the background of predisposing capillaritis, local inflammatory cell traffic, triggered by infection, results in an amplification of the capillaritis, further endothelial cell damage, and haemorrhage.

Antineutrophil cytoplasmic antibodies were directed against antigens found in the neutrophil primary granule. ${ }^{46}$ Indirect immunofluorescence of ethanol fixed neutrophils shows two major categories of antineutrophil cytoplasmic antibodies-C-ANCA (cytoplasmic staining) and P-ANCA (perinuclear staining). Most C-ANCA antibodies are directed against the antigen serine protease III, whereas most P-ANCA are directed against the antigen myeloperoxidase. Autoantibodies to either serine protease III or myeloperoxidase provide a sensitive and specific test for vasculitic syndromes, including Wegener's granulomatosis, microscopic polyarteritis, classic polyarteritis, the Churg-Strauss syndrome, and vasculitis associated with glomerulonephritis. ${ }^{5}$ The use of solid phase assays to detect antiserine protease III antibodies or antimyeloperoxidase antibodies has improved the sensitivity of antineutrophil cytoplasmic antibodies testing and allowed accurate measurements of disease activity. $^{7}$ The presence of antineutrophil cytoplasmic antibodies in pulmonary renal vasculitis syndromes is well described ${ }^{4-6}$; in addition, antineutrophil cytoplasmic antibodies have been described in patients with idiopathic pulmonary fibrosis. ${ }^{8}$ To our knowledge they have not been reported in the context of idiopathic pulmonary haemorrhage.

An unusual feature of the antineutrophil cytoplasmic antibodies in this case is that they were directed against myeloperoxidase, despite producing a cytoplasmic pattern on the indirect immunofluorescence on ethanol fixed cells. No other indirect antigens could be detected by ELISA (alpha granule, anti-29 kDa). In contrast to a previous study, ${ }^{5}$ this patient had only IgG ANCA, with virtually no IgM ANCA. The disease had been present for many years and possibly production of the antibodies had switched from IgM to IgG. Indirect immunofluorescence showed no IgM ANCA at the time IgG became positive and the titre did not rise significantly during the course of the illness.

We suggest that ANCA tests should be performed in all patients with acute or chronic pulmonary haemorrhage. Chronic pulmonary haemorrhage, often regarded as diagnostic of idiopathic pulmonary haemosiderosis, may in fact be an occult vasculitis and this has major implications for treatment: evidence of vasculitis would merit treatment with cyclophosphamide and corticosteroids, as recommended by Fauci et al. ${ }^{10}$ 
1 Savage COS, Winearls CG, Evans DJ, Rees AJ, Lockwood CM. Microscopic polyarteritis. Presentation, pathology and prognosis. $Q J$ Med 1985;56:467-84

2 Leatherman JW, Davies SF, Hoidal JR. Alveolar haemorrhage syndromes: diffuse microvascular lung haemorrhage in immune and idiopathic disorders. Medicine 1984;63: 343-61.

3 Corrin B, Jagusch M, Dewar A, et al. Fine structural changes in idiopathic pulmonary haemosiderosis. J Pathol 1987; 153:249-56.

4 Falk RJ, Jennette CJ. ANCA with specificity for myeloperoxidase in patients with systemic vasculitis and idiopathic necrotizing and crescentic glomerulonephritis. idiopathic necrotizing and crescent

5 Tervaert JWC, Goldschmeding R, Elema JD, Limburg PC, van der Giessen M, Hitema MG, et al. Association of autoantibodies to myeloperoxidase with different forms of vasculitis. Arth Rheum 1990;33:1264-72.

6 Jennette JC, Falk RJ. Antineutrophil cytoplasmic auto- antibodies and associated diseases: a review. Am J Kidney Dis 1990;15:517-29.

7 Niles JL, Pan G, Collins B, Shannon T, Skates S, Fienberg $\mathrm{R}$, et al. Antigen-specific radioimmunoassays for antineutrophil cytoplasmic antibodies in the diagnosis of rapidly progressive glomerulonephritis. J Am Soc Nephrol 1991;2:27-36.

$8 \mathrm{Nada}$ AK, Torres VE. Pulmonary fibrosis as an unusual manifestation of a pulmonary-renal vasculitis in elderly patients. Mayo Clin Proc 1990;65:847-56.

9 Jayne DRW, Jones SJ, Severn A, Shaunak S, Murphy J, Lockwood CM. Severe pulmonary haemorrhage and systemic vasculitis in association with circulating antineutrophil cytoplasm antibodies of IgM class only. Clin Nephrol 1989;32:101-6.

10 Fauci AS, Barton F, Haynes MD, Katz P, Wolff SM. Wegener's granulomatosis: prospective clinical and therapeutic experience with 85 patients for 21 years. $A n n$ Intern Med 1983;98:76-85.

\section{Extrinsic allergic alveolitis caused by goose feathers in a duvet}

\author{
Tj Haitjema, $H$ van Velzen-Blad, \\ $\mathrm{J} M \mathrm{M}$ van den Bosch
}

\section{Department of Pulmonology Tj Haitjema J M M van den Bosch \\ Department of Medical Microbiology and Immunology $H$ van Velzen-Blad \\ St Antonius Hospital, Koekoekslaan 1, 3435 CM Nieuwegein, The Netherlands \\ Reprint requests to: Dr MM van den Bosch Received 27 January 1992 Returned to authors 22 April 1992 Revised version received 4 June 1992 \\ Accepted 16 June 1992}

\begin{abstract}
A patient with extrinsic allergic alveolitis had precipitating antibodies to many avian antigens. A duvet containing goose feathers proved to be the source of antigenic material.
\end{abstract}

\section{(Thorax 1992;47:990-991)}

Extrinsic allergic alveolitis is a well known disease caused by inhalation of organic dusts or of inorganic chemicals, leading to bronchoalveolar inflammation. Birds are a common cause and reactions to antigens from pigeons, budgerigars, hens, parrots, canaries, and turkeys have been reported. We describe a case of extrinsic allergic alveolitis caused by goose feathers in a duvet.

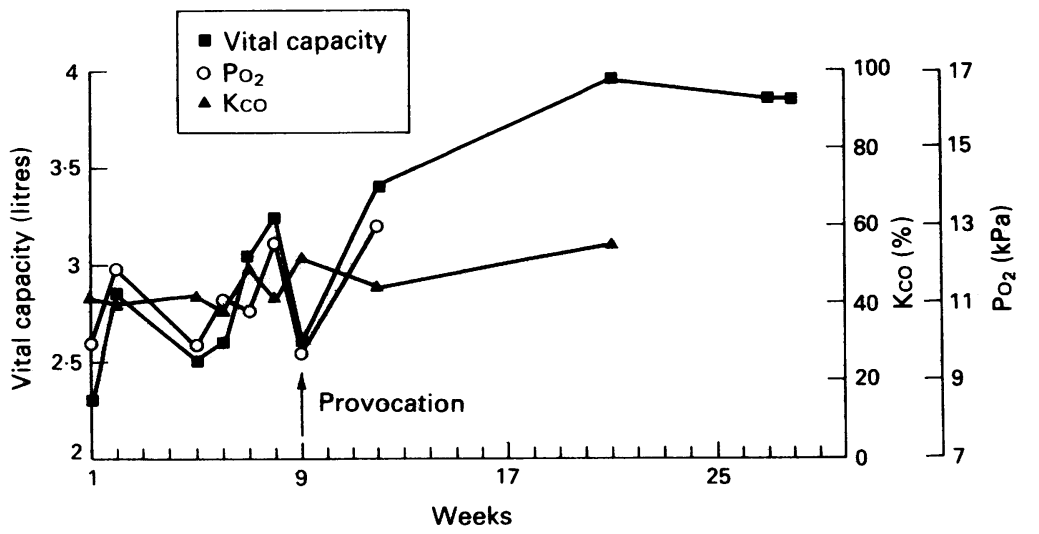

Results of lung function tests.

\section{Case report}

A 31 year old, previously healthy, non-smoking woman was admitted to hospital with increasing shortness of breath, purulent sputum, and fever. Her complaints had started three weeks previously and had not been improved by erythromycin. She had lost $4 \mathrm{~kg}$. She had no previous history of allergy, occupational exposure to organic or inorganic dusts, or respiratory tract infection. She kept a cat.

A chest radiograph showed a reticulonodular pattern, predominantly in the lower zone. Her erythrocyte sedimentation rate was $29 \mathrm{~mm}$ in the first hour (normal $<10 \mathrm{~mm}$ ); angiotensin converting enzyme activity was 85 (normal $<50)$ IU. No other biochemical values were abnormal. Lung function tests showed a vital capacity of 2.3 (normal 3.93) 1 , an $\mathrm{FEV}_{1}$ of 1.71 , a gas transfer coefficient (KCo) of $41 \%$, and hypoxaemia worsening during exercise (arterial oxygen tension $10.0 \mathrm{kPa}$ at rest, $7.5 \mathrm{kPa}$ after cycle ergometer testing with a work load of $13 \cdot 2 \mathrm{~kJ}$ ). Specific lung compliance was reduced to 0.28 (expected $0.7-1 \cdot 1$ ) $\mathrm{kPa}^{-1}$. Bronchoalveolar lavage was performed on day 2, which showed lymphocytosis, with an increased number of $T$ lymphocytes, and a low CD4:CD8 ratio (table). The immunoglobulin: albumin ratios in the lavage fluid supernatant, including IgM:albumin, were increased. These results were consistent with extrinsic allergic alveolitis; a detailed history, however, indicated no possible antigen.

The patient improved spontaneously in hospital, becoming afebrile after seven days, and improvements were seen in the measurements made from a second bronchoalveolar lavage, performed after nine days in hospital (table). She was discharged, and went to stay with her parents, where she continued to improve (figure). Tests for precipitating antibodies against pigeon, budgerigar, canary, and parrot antigens then proved to be positive. A renewed search of the patient's home revealed only a duvet and a pillow, containing nothing but goose feathers (confirmed by the manufacturer) as a possible source of antigenic material. The patient had used the duvet for four years. Retrospectively, the precipitating antibodies against goose antigens proved to be strongly 